\title{
LA PROMOCIÓN Y PROTECCIÓN DE LOS DERECHOS HUMANOS: ORGANIZACIONES Y MECANISMOS INTERNACIONALES: EL Sistema CENTROAMERICANO dE PROTECCIÓN DE LOS DERECHOS HUMANOS
}

ORLANDO GUERRERO MAYORGA

Catedrático de Derecho Internacional Público Universidad Centroamericanan

\section{1. "El Sistema de Derechos Fundamentales"}

En el marco del Sistema de la Integración Centroamericana (SICA), no existe un catálogo de derechos fundamentales propio del Derecho Comunitario Centroamericano. Sin embargo, considero que los Derechos Fundamentales de la persona están incluidos dentro de los principios generales del Derecho Comunitario, cuyo respeto garantiza el Tribunal de Justicia Centroamericano.

Estos principios fundamentales son los siguientes:

a) La tutela, respeto y promoción de los Derechos Humanos constituyen base fundamental del SICA.

b) Paz, Democracia y Desarrollo y Libertad, son un todo armónico e indivisible que orientará las actuaciones de los países miembros del SICA.

c) La identidad centroamericana como manifestación activa de los intereses regionales y de la voluntad de participar en la consolidación de la integración de la Región.

d) La solidaridad centroamericana como expresión de su profunda interdependencia, origen y destino común.

e) La gradualidad, especificidad y progresividad del proceso de integración económica, sustentado en el desarrollo regional armónico y equilibrado y el tratamiento especial a países miembros de menor desarrollo relativo, la equidad y reciprocidad y la Cláusula Centroamericana de Excepción.

f) La globalidad del proceso de integración y la participación democrática, en el mismo, de todos los sectores sociales.

g) La seguridad jurídica de las relaciones entre los Estados Miembros y la solución pacífica de sus controversias.

${ }^{1}$ Doctor en Derecho Internacional Publico. Diplomado en Relaciones Internacionales. Universidad Complutense y Escuela Diplomática de Madrid, España. Secretario General de la Corte Centroamericana de Justicia. Conferencia sobre "La Protección de los Derechos Humanos de los Desplazados por la Violencia y Otras Causas " Universidad del Rosario, Bogota, Colombia 4 de marzo del 2004. 
h) La buena fe de los Estados Miembros en el cumplimiento de sus obligaciones, absteniéndose de establecer, convenir o adoptar medida alguna que sea contraria a las disposiciones del Protocolo de Tegucigalpa o que obstaculice el cumplimiento de los Principios Fundamentales del SICA o la consecución de sus objetivos.

i) El respeto a los principios y normas de la Carta de la ONU y de la OEA, y las Declaraciones emitidas en las Reuniones Presidenciales Centroamericanas desde mayo de 1986. ${ }^{2}$

También el Artículo 3 a) del Protocolo de Tegucigalpa reafirma como uno de sus propósitos: "Consolidar la democracia y fortalecer sus Instituciones sobre la base de la existencia de Gobiernos electos por sufragio universal, libre y secreto, y del irrestricto respeto a los Derechos Humanos".

La Sentencia de La Corte en el caso Viguer Rodrigo reconoce el irrestricto respeto, tutela y promoción de los Derechos Humanos, de conformidad con los artículos 3 a) y 4 a) del Protocolo de Tegucigalpa, que la Corte Centroamericana de Justicia está en la obligación de salvaguardar y hacer efectivos a lo interno del Sistema. ${ }^{4}$

Se refiere esta sentencia a la protección de Derechos Humanos dentro del Sistema de la Integración Centroamericana ya que fuera del mismo, le correspondería exclusivamente a la Corte Interamericana de Derechos Humanos de conformidad con el Artículo 25 del Convenio de Estatuto de la Corte Centroamericana de Justicia.

Sin embargo, y como lo expresa el Doctor Mauricio Herdocia Sacasa: “ En el fondo pese a que la competencia de La Corte no se extiende a los Derechos Humanos, por corresponder a la Corte Interamericana de Derechos Humanos. Estamos realmente en última instancia, ante una competencia sino directa al menos indirecta de derechos humanos, por cuanto cada vez que un Estado irrespeta un fallo que pase en autoridad de cosa juzgada, transgrede al mismo tiempo, la Convención Americana sobre Derechos Humanos en los asuntos de garantías judiciales (Art. 8), igualdad ante la ley (Arto. 24) y protección judicial (Arto. 25)". 5

${ }^{2}$ Guerrero Mayorga, Orlando: “ Recopilación de Textos Básicos de Derecho Internacional Público”, Editorial Somarriba, Managua, 1999, pp. 306-307.

3 Ibidem.

${ }^{4}$ León Gómez Adolfo: “ Doctrina de la Corte Centroamericana de Justicia. Resoluciones, Precedentes y Votos Disidentes”. Imprenta UCA, Managua, 1ra. Edición, 12 de octubre de 2002, p. 220.

5 Herdocia Sacasa, Mauricio: " La Obra de la Comisión de Derecho Internacional de las Naciones Unidas en el Quinquenio 1997-2001. El Aporte Global de América Latina”. Editorial Imprimatur, Artes Gráficas, Managua, 2003, p. 12. 
Considero que en los casos de irrespeto de fallos judiciales, la doctrina de la Corte Centroamericana de Justicia ha reconocido que para la realización de los propósitos del Sistema de la Integración Centroamericana, los Estados Miembros se han comprometido a constituir a Centroamérica como Región de Paz, Libertad, Democracia y Desarrollo "lo que comprende el estar sometido a los principios del Estado de Derecho que incluyen el cumplimiento irrestricto de los fallos judiciales y actuar de conformidad con el principio de buena fe en el cumplimiento de sus obligaciones, según lo estipulado en los Artículos 3 y 4 literal h) del Protocolo de Tegucigalpa." 6

Existen tres generaciones de Derechos Humanos. La primera que tiene que ver con los Derechos Civiles y Políticos, llamados Derechos de primera generación, por haber surgido primero históricamente. Algunos son Derechos Naturales como la vida, la dignidad, la libertad, la justicia, etc. La segunda generación a la que pertenecen los derechos económicos, sociales y culturales y es una reivindicación muy sentida por los países pobres o tercermundistas, que les han dado mayor importancia que a los Derechos Civiles y Políticos. ¿ De que sirve que una persona vote ejerciendo un derecho político para elegir a su gobernante o ser electo si es analfabeto o tiene el estómago vacío?

Y la tercera generación a la que corresponde los Derechos de la Solidaridad, que tienen que ver con el derecho a la paz, a la libre determinación de los pueblos, al derecho al desarrollo, al patrimonio común de la humanidad y al medio ambiente que está íntimamente conectado con el derecho a la vida; porque en un ambiente insano se afecta la vida de las personas.

Pero estas tres gamas de generación de derechos se interrelacionan de tal manera que tienen que funcionar como un todo armónico e indivisible.

Todo esto nos lleva a analizar, la naturaleza de una y otra gama de derechos, de los derechos civiles y políticos con los derechos económico, sociales y culturales.

\section{Mecanismo de Protección Internacional de los Derechos Civiles y Políticos}

En cuanto a los derechos civiles y políticos el mecanismo de protección por su misma naturaleza impone al Estado el deber de no violar el derecho a la vida, de no torturar, respetar las creencias religiosas, el libre tránsito, la libre expresión, la inviolabilidad del domicilio, etc.

\footnotetext{
${ }^{6}$ León Gómez Adolfo: “ Doctrina de la Corte Centroamericana de Justicia. Resoluciones, Precedentes y Votos Disidentes"... p. 87.

7 Serrano Caldera Alejandro: "Estado de Derecho y Derechos Humanos". Instituto de Derechos Humanos Universidad Nacional Autónoma de Nicaragua, UNAN-León ( 2000) p. 69.
} 
Se requiere respeto es decir, abstenciones por parte del Estado. También exigen garantías de su respeto y esta idea evoca prestaciones positivas en los órdenes legislativos, ejecutivo y judicial. Dice el párrafo primero del Artículo 2 del Pacto Internacional de Derechos Civiles y Políticos: "Cada uno de los Estados Partes en el presente Pacto se comprometen a respetar y garantizar a todos los individuos que se encuentren en su territorio y están sometidos a su jurisdicción, los derechos conocidos en el presente Pacto, sin distinción alguna de raza, color, sexo, idioma, religión, opinión política o de otra índole, origen nacional o social, posición económica, nacimiento o cualquier otra condición social”.

Los Estados que crean el Derecho Internacional y son sus propios destinatarios, le han dado una mayor relevancia a los derechos civiles y políticos; que por su misma naturaleza se prestan a utilizar mecanismos de protección más eficaces; porque estos derechos que arrancan de la Declaración Universal de los Derechos Humanos, la cual influye en el Pacto Internacional de Derechos Civiles y Políticos, constituyen Normas Positivas del Derecho Internacional en General. Los Estados se obligaron por este instrumento a presentar informes al Comité del Pacto Internacional de Derechos Civiles y Políticos, lo cual tiene la característica de ser preventivo de la repetición de futuras violaciones que estrictamente protector ante violaciones de Derechos Humanos ya ocurridas. Se le dice a los Estados que tomen determinadas medidas o recomendaciones a fin de evitar que se sigan violando estos derechos.

Paralelamente se establece un mecanismo ya no obligatorio por la vía de informe, sino opcional, facultativo, de reclamaciones interestatal o de reclamaciones de particulares en contra del Estado a través de la vía del Pacto Internacional de Derechos Civiles y Políticos, como también mediante el Protocolo Facultativo a dicho Pacto, que permite a un particular, sea éste una persona física o natural para que se pueda quejar del Estado que está violando sus derechos civiles y políticos consagrados en la Declaración Universal de los Derechos Humanos, la cual no contempló un mecanismo, procedimiento o sanción, para el Estado que infrinja dichos derechos. Con influencia de la propia Declaración, se logran incorporar esos derechos en el Pacto Internacional de Derechos Civiles y Políticos y mediante el Protocolo Facultativo se diseña un mecanismo cuasi contencioso que tiene la característica de ser contradictorio, enfrenta dos partes al Estado y al particular y además condenatorio y sancionatorio ya que puede establecer una condena al Estado y sanciones de tipo económico. Se tramita como si fuera un mecanismo jurisdiccional, con la salvedad que si bien es cierto se asemeja a la forma de una sentencia su resolución, no tiene la característica de un fallo jurisdiccional el cual es vinculante y obligatorio para los 
Estados partes en el litigio, quedando únicamente en el plano de las sanciones políticas o morales. ${ }^{8}$

Este tipo de sanciones algunas veces son más eficaces que la coerción misma, ya que el Estado se desacredita en su política internacional, aparece como un gran violador de los Derechos Humanos y Libertades Fundamentales, se le cierra las válvulas de financiamiento internacional, se le dificulta la renegociación de su deuda externa o la condonación de la misma y se va quedando aislado internacionalmente.

\section{Requisitos que deben cumplirse para la admisibilidad de las denuncias o quejas}

El Comité del Pacto Internacional de Derechos Civiles y Políticos, no puede actuar de oficio si no que a solicitud de parte interesada y tiene que cumplirse algunos requisitos procesales, como es el agotamiento de los recursos de la jurisdicción interna y que la denuncia o queja no sea anónima, debe estar perfectamente identificada la víctima o el representante legal de la víctima y por otro lado, que no se haya presentado la denuncia a otra instancia de protección internacional previa a la protección del Comité, en virtud del principio non bis in idem, ya que no puede conocer de un mismo asunto dos instancias distintas de protección internacional, todo para evitar duplicidad de fallos, y que hayan fallos contradictorios, entonces una instancia que conoce de previo previene la competencia a la otra instancia, pero una vez que la instancia ya conoció y resolvió el caso, no puede llegar el mismo a ser conocido por otra instancia de su misma naturaleza de protección internacional de los Derechos Humanos.

También es importante destacar que el Estado supuesto infractor de los Derechos Civiles y Políticos tiene que ser parte vinculante del Pacto Internacional de Derechos Civiles y Políticos y del Protocolo Facultativo a dicho Pacto, ya que si no es parte de éste únicamente al particular le queda la protección internacional por la vía de informe, es decir, el Estado está obligado por el Pacto a presentar informes, pero queda el particular desprotegido en su reclamación individual; ya que no puede ocurrir al proceso cuasi-contencioso de las quejas individuales. ${ }^{9}$

${ }^{8}$ Villán Durán Carlos: "Mecanismos de Protección de los Derechos Humanos en el marco de la ONU". Memoria del Primer Congreso Internacional sobre Justicia, Integración y Derechos Humanos, Montelimar, Nicaragua, Centroamérica, 6, 7 y 8 de marzo de 1996. Pág. 179 a 210.

9 Guerrero Mayorga Orlando: "Recopilación de Textos Básicos de Derecho Internacional Público", Edit. Somarriba, Managua, 1999, pp. 60-80. 


\section{Mecanismo de Protección Internacional de los Derechos Económicos, Sociales y Culturales}

En los derechos económicos, sociales y culturales están incluidos el Derecho a la Preservación de la Salud y el Bienestar; el Derecho a la Educación; el Derecho a la Enseñanza Primaria Obligatoria y Gratuita; el Derecho a los Beneficios de la Cultura; el Derecho al Trabajo y a una Justa Remuneración; el Derecho de Huelga y a fundar Sindicatos; el Derecho al Descanso y a su Aprovechamiento; los Derechos de la Familia y del Niño; y el Derecho a la Seguridad Social.

En cuanto a estos derechos los Estados fueron muy cuidadosos por lo oneroso que resulta el quebrantamiento de los derechos económicos, sociales y culturales, creando un mecanismo más débil de protección.

El mecanismo que se sigue es por la vía del Pacto Internacional de Derechos Económicos, Sociales y Culturales, el cual establece la obligatoriedad de los informes por parte de los Estados partes vinculados a ese Pacto y el Comité actúa a priori preventivamente para evitar que se violen esos derechos. El Estado que ha ratificado dicho Pacto tiene que presentar un informe dentro de dos años a partir de la fecha de la ratificación o adhesión y posteriormente cada cinco años. ${ }^{10}$ Sin embargo, nos encontramos que por la naturaleza misma de estos derechos que están determinados más en el campo de las obligaciones de comportamiento y no de resultado, se crea un mecanismo menos ágil de protección. Como la obligación es de comportamiento se condiciona a ésta hasta el máximo de recursos de que disponga el Estado, se cae en obligaciones que están condicionadas.

El Pacto Internacional de Derechos Económicos, Sociales y Culturales, en su numeral primero establece: "Cada uno de los Estados partes en el presente Pacto se compromete a adoptar medidas, tanto por separado, como mediante la asistencia y cooperación internacional, especialmente económicas y técnicas, hasta el máximo de los recursos de que disponga para lograr progresivamente la plena efectividad, por todos los medios apropiados, inclusive en particular la adopción de medidas legislativas de los derechos aquí reconocidos".

Existen tres elementos clave sobre la naturaleza de los Derechos Económicos, Sociales y Culturales. La primera es la obligación de adoptar medidas para su disfrute, lo que evoca la idea de prestaciones positivas, la segunda es la factibilidad hasta el máximo de los recursos de que disponga, o lo que es lo mismo, el condicionamiento de la obligación por las posibilidades; la tercera es la progresividad. Los Estados se escudan en que son obligaciones de comportamiento, que sólo implican el compromiso de poner los medios para alcanzar un resultado y

${ }^{10}$ Ibiden pp 51-59. 
que dejan amplios márgenes de discrecionalidad a su destinatario. Consiguientemente, el control de su cumplimiento no puede ser muy estricto. En este sentido no se puede usar el mecanismo de reclamación individual para hacer valer los derechos económicos, sociales y culturales, solo el mecanismo de informe por la vía del Pacto, esto es en el Sistema de Protección Internacional de las Naciones Unidas. $^{11}$

\section{El Mecanismo de Protección de los Derechos Económicos, Sociales y Culturales en el Sistema Interamericano}

En el plano interamericano se está avanzando progresivamente ya que en la Convención Americana Sobre Derechos Humanos, se crean dos órganos para la protección de los derechos civiles y políticos; como es la Comisión Interamericana y la Corte Interamericana de Derechos Humanos. Progresivamente se van garantizando sólidamente la protección de estos derechos, porque se instaura ya no sólo un mecanismo cuasi contencioso como el que existe en el Pacto Internacional de Derechos Civiles y Políticos y su Protocolo Facultativo; sino un mecanismo cuasi-contencioso vía la Comisión Interamericana de Derechos Humanos; y jurisdiccional a través de la Corte Interamericana de Derechos Humanos, cuyas sentencias son vinculantes y obligatorias para los Estados parte y se tienen que acatar como los fallos a nivel nacional que son de ineludible cumplimiento. En cambio en el campo de los Derechos Económicos, Sociales y Culturales, no encontramos un avance más significativo.

Frente a esta debilidad de la Convención Americana sobre Derechos Humanos, de no instaurar el mecanismo de reclamaciones individuales para la protección de los Derechos Económicos, Sociales y Culturales, se ha aprobado un Pacto Adicional a la Convención Americana sobre Derechos Humanos en materia de Derechos Económicos, Sociales y Culturales; en donde encajan el derecho a la libre sindicalización y a la educación, mediante el mecanismo cuasi contencioso y en su caso contencioso, ya que se establece en el artículo 8.1 de dicho Pacto lo siguiente: "Los Estados partes garantizarán: a) el derecho de los trabajadores a organizar sindicatos y a afiliarse al de su elección, para la protección y promoción de sus intereses. Como proyección de este derecho, los Estados partes permitirán a los sindicatos formar federaciones y confederación nacionales y asociarse a las ya existentes, así como formar organizaciones sindicales internacionales y asociarse a la de su elección. Los Estados partes también permitirán que los sindicatos, federaciones y confederaciones funcionen libremente...”

${ }^{11}$ Pastor Ridruejo José Antonio: “Curso de Derecho Internacional Público y Organizaciones Internacionales”. Sexta Edición, Tecnos, Madrid, 1996, pp 228 y 229. 
Así mismo, el Artículo 13 establece el derecho a la educación: "1. Toda persona tiene derecho a la educación. 2. Los Estados partes en el presente Protocolo convienen en que la educación deberá orientarse hacia el pleno desarrollo de la personalidad humana y del sentido de su dignidad y deberá fortalecer el respeto por los derechos humanos, el pluralismo ideológico, las libertades fundamentales, la justicia y la paz.

Convienen, así mismo, en que la educación debe capacitar a todas las personas para participar efectivamente en una sociedad democrática y pluralista, lograr una subsistencia digna, favorecer la comprensión, la tolerancia y la amistad entre todas las naciones y todos los grupos raciales, étnicos o religiosos y promover las actividades a favor del mantenimiento de la paz..."

El mecanismo de protección del derecho a la libre sindicalización y a la educación está consagrado en el Articulo 19 del Protocolo Adicional a la Convención Americana sobre Derechos Humanos, ${ }^{12}$ que establece como medio de protección: "1. Los Estados partes en el presente Protocolo se comprometen a presentar, de conformidad con lo dispuesto por este artículo y por las correspondientes normas que al efecto deben elaborar la Asamblea General de la Organización de los Estados Americanos, informes periódicos respecto de las medidas progresivas que hayan adoptado para asegurar el debido respeto de los derechos consagrados en el mismo Protocolo."

Así mismo, este artículo en el numeral 6 establece: "En el caso que los derechos de libre sindicalización y el derecho a la educación fuesen violados por una acción imputable directamente a un Estado parte del presente Protocolo, tal situación podría dar lugar mediante la participación de la Comisión Interamericana de Derechos Humanos, y cuando proceda de la Corte Interamericana de Derechos Humanos, a la aplicación del sistema de peticiones individuales regulado por los artículos 44 a 51 y 61 al 69 de la Convención Americana sobre Derechos Humanos”.

Esto constituye una evolución progresiva del Derecho Internacional de los Derechos Humanos porque se permite por la vía de reclamaciones individuales garantizar la protección de los derechos de libre sindicalización y educación en el sistema interamericano de protección de dichos derechos que corresponden a los derechos de la segunda generación.

\footnotetext{
12 Protocolo Adicional a la Convención Americana sobre Derechos Humanos, "Protocolo de San Salvador", los países signatarios del mismo son: Argentina, Bolivia, Brasil, Colombia, Costa Rica, República Dominicana, Ecuador, El Salvador, Guatemala, Haití, México, Nicaragua, Panamá, Paraguay, Perú, Suriname, Uruguay y Venezuela (18 países): De estos aún están pendientes de ratificarlo los siguientes países: Argentina, Bolivia, República Dominicana, Haití, Nicaragua y Venezuela ( 6 países). Fue suscrito en San Salvador, El Salvador, el 17 de noviembre de 1988, en el décimo octavo período ordinario de sesiones de la Asamblea General. Entró en vigor, 16 de noviembre de 1999.
} 
Hasta la fecha sólo, Brasil, Colombia, Costa Rica, Ecuador, El Salvador, Guatemala, México, Panamá, Paraguay, Perú, Surinam y Uruguay, han ratificado el Protocolo en materia de derechos económicos, sociales y culturales, el cual ya entró en vigor con el depósito de once instrumentos de ratificación.

\section{La Corte Centroamericana de Justicia y la Vigencia de los Derechos, Eco- nómicos, Sociales y Culturales}

El artículo 25 del Estatuto de la Corte Centroamericana de Justicia establece que "La competencia de la Corte no se extiende a la materia de Derechos Humanos, la cual corresponde exclusivamente a la Corte Interamericana de Derechos Humanos". Sin embargo, existe una interpretación extensiva al referido artículo.

Según criterio del Doctor Rafael Chamorro Mora, Expresidente de la Corte Centroamericana de Justicia, en aquellos casos de violaciones de derechos humanos, no cometidos por los Estados, sino por órganos de la integración, pudiera La Corte conocer de ellas, ya que la Corte Interamericana de Derechos Humanos no tiene competencia para conocer las mismas por no ser los Estados los infractores. ${ }^{13}$

También, el actual Magistrado Presidente, de la Corte Centroamericana de Justicia, Jorge Antonio Giammattei Avilés, es del criterio que el Artículo 25 del Estatuto de La Corte: " debe interpretarse en tal forma restringido para los casos de los Estados sujetos a la Convención Interamericana de Derechos Humanos y a la Jurisdicción de la Corte Interamericana de Derechos Humanos según el Artículo 44 de la referida Convención, en tal forma que no puedan quedar sin sanción infracciones a Derechos Fundamentales de un Organo, Organismo o Institución del Sistema SICA, como consecuencia del incumplimiento de la normativa comunitaria relativa a esa materia o de los principios y normas de las Cartas de la Organización de las Naciones Unidas (ONU), o de la Organización de Estados Americanos (OEA), o de lo establecido en las Declaraciones de la Reunión de Presidentes como Organo Supremo del Sistema SICA, a partir de mayo de 1986, que según el artículo 4 letra i del Protocolo de Tegucigalpa son también normas y principios del Sistema SICA". ${ }^{14}$

En ese sentido La Corte Centroamericana de Justicia ha sentado jurisprudencia al respecto, mediante resolución del día veinticuatro de octubre del año dos

${ }^{13}$ Conferencia del Dr. Rafael Chamorro Mora, dictada en el Seminario "Justicia e integración”, celebrado con motivo de la VII Asamblea General del IELEPI, en la ciudad de Managua, Nicaragua, Centroamérica, los días 16 y 17 de noviembre de 1998.

${ }^{14}$ VIII Encuentro de los Presidentes y Magistrados de las Cortes Y Salas Constitucionales de América Latina, en las ciudades de Bruselas, Luxemburgo, Karlsruke, Estrasburgo y Berlín, del 24 de junio al 1 de julio del 2001, Publicación de la Konrad Adenauer-Stiftung, México. Ponencia del Dr. Jorge Antonio Giammattei Avilés, Presidente de la Corte Centroamericana de Justicia, Nicaragua, p.42. 
mil, referente al escrito presentado por el señor José Viguer Rodrigo, en el que alegaba que el juicio penal que se le instruía por el delito de violación ante las autoridades judiciales de Chinandega, Nicaragua, se han cometido por la justicia nicaragüense irregularidades, por el prejuicio racial de ser español, en el que La Corte resolvió lo siguiente:

\section{CONSIDERANDO I}

Que si las supuestas infracciones fueran atribuidas a un Órgano, Organismo o Institución del Sistema de la Integración Centroamericana (SICA), como consecuencia del incumplimiento de la Normativa que rige este Sistema, podrían talvez llegar a ser del conocimiento de esta Corte, en atención a que uno de los pilares en que se fundamenta el Sistema de la Integración Centroamericana (SICA), es el irrestricto respeto, tutela y promoción de los Derechos Humanos, de conformidad con los artículos 3 a) y 4 a) del Protocolo de Tegucigalpa, que este Tribunal está en la obligación de salvaguardar y hacer efectivos a lo interno del Sistema, ya que dichos Órganos, Organismos e Instituciones no están sujetos a la Jurisdicción de la Corte Interamericana de Derechos Humanos, y los afectados por ellos quedarían sin protección alguna.

\section{CONSIDERANDO II}

Que en el presente caso se trata de una presunta violación de Derechos Fundamentales atribuida a las autoridades judiciales de un Estado sujeto a la Convención Interamericana de Derechos Humanos, según los artículos 44 y 61 numeral 2 de la referida Convención, por lo que de conformidad con el artículo 25 del Convenio del Estatuto de la Corte Centroamericana de Justicia no podría ser del conocimiento de este Tribunal.

\section{CONSIDERANDO III}

Que el artículo 30 del aludido Convenio de Estatuto le otorga a La Corte la facultad para determinar su competencia en cada caso concreto, interpretando los Tratados o Convenciones pertinentes al asunto en disputa, aplicando los principios del Derecho de Integración y del Derecho Internacional, por UNANIMIDAD, RESUELVE: Declarar sin lugar lo solicitado en el referido escrito, por no ser de la competencia de este Tribunal, ya que lo expresado es atinente a supuestas violaciones de Derechos Fundamentales atribuidos a los Órganos encargados de Administrar Justicia en Nicaragua, Estado para el cual está vigente la Convención Americana de Derechos Humanos y como 
consecuencia su conocimiento puede caer bajo la competencia exclusiva de la Corte Interamericana de Derechos Humanos, de acuerdo con lo establecido en los Artículos 44 y 61 numeral 2 de esa Convención." 15

\section{Conclusiones}

En la Convención Americana sobre Derechos Humanos (Pacto de San José), en el artículo 26. "Desarrollo Progresivo", se establece que: los Estados partes se comprometen a adoptar providencias, tanto a nivel interno como mediante la cooperación internacional a fin de lograr progresivamente la plena efectividad de los Derechos que se derivan de las normas económicas, sociales y sobre educación, ciencia y cultura, contenidas en la Carta de la OEA vigente en la medida de los recursos disponibles, por vía legislativa u otros medios apropiados.

En la Convención no se incorporan cuáles son los derechos económicos, sociales y culturales y no se instaura un mecanismo de reclamaciones individuales para la protección de los mismos. Sin embargo en el Pacto Adicional a la Convención Americana sobre Derechos Humanos, en materia de Derechos Económicos, Sociales y Culturales, denominado "Protocolo de San Salvador", no sólo se incorporan cuáles son estos derechos, sino que en el artículo 19, se establecen los medios de protección que pueden ser por la vía de informes periódicos de las medidas que los Estados hayan adoptado para asegurar el debido respeto de los Derechos consagrados en dicho Protocolo, pero también por la vía de reclamaciones individuales en el caso que los derechos establecidos en el párrafo a) del artículo 8 y en el artículo 13 (Libre Sindicalización y Educación), fueran violados por una acción imputable directamente a un Estado parte del "Protocolo de San Salvador".

En consecuencia, puede actuar la Comisión Interamericana de Derechos Humanos tutelando estos derechos y en su caso, la Corte Interamericana de Derechos Humanos, si el Estado parte de ese Protocolo ha hecho la declaración de aceptación de la competencia y jurisdicción de la Corte Interamericana de Derechos Humanos para conocer de violaciones a los Derechos de Libre Sindicalización y Educación.

En lo que respecta a los otros derechos económicos, sociales y culturales, quedan protegidos únicamente por la vía de informes de los Estados partes del "Protocolo de San Salvador". Estos derechos son los siguientes:

\footnotetext{
${ }^{15}$ León Gómez Adolfo: "Doctrina de la Corte Centroamericana de Justicia, Resoluciones, Precedentes, votos disidentes". Managua, Nicaragua, Centroamérica, octubre de 2002. Imprenta UCA, 1ra. Edición.- pp-220-221. También Gaceta Oficial. Corte Centroamericana de Justicia, Año 6, Managua, Lunes 16 de abril del 2001, Num. 11 pp 4 y 5.
} 
- Art. 6: Derecho al Trabajo

- Art. 7: Condiciones Justas Equitativa y Satisfactorias de Trabajo

- Art. 8: Derecho a la Huelga

- Art. 9: Derecho a la Seguridad Social

- Art. 10: Derechos a la Salud

- Art. 11: Derecho a un Medio Ambiente Sano

- Art. 12: Derecho a la Alimentación.

- Art. 14: Derechos a los Beneficios de la Cultura

- Art. 15: Derecho a la Constitución y Protección de la Familia

- Art. 16: Derechos de la Niñez

- Art. 17: Protección de los Ancianos

- Art. 18: Protección de los Minusválidos

Por lo que tanto estos Derechos Económicos, Sociales y Culturales como los Derechos a la Libre Sindicalización y a la Educación, si el Estado que los viola no es parte del "Protocolo de San Salvador" y no ha hecho la declaración de aceptación de la competencia de la Corte Interamericana de Derechos Humanos conforme el artículo 62 numeral 1 de la Convención Interamericana de Derechos Humanos, quedarían fuera del mecanismo de protección de los Derechos Humanos en el Sistema Interamericano en la doble vertiente por la vía cuasi-contenciosa de peticiones individuales ante la Comisión Interamericana de Derechos Humanos, "y por la vía contenciosa ante la Corte Interamericana de Derechos Humanos y podrían también llegar a ser del conocimiento de la Corte Centroamericana de Justicia”, en atención a que uno de los pilares en que se fundamenta el Sistema de la Integración Centroamericana (SICA), es el irrestricto respeto, tutela y promoción de los Derechos Humanos, de conformidad con los artículos 3 a) y 4 a) del "Protocolo de Tegucigalpa" y además, porque no cae dentro del ámbito de aplicación del Artículo 25 del Convenio de Estatuto de la Corte Centroamericana de Justicia.

La Corte Centroamericana de Justicia tiene la facultad para determinar su competencia en cada caso concreto, interpretando otros tratados como el tratado de integración social que contiene no sólo derechos civiles y políticos, también derechos económicos sociales y culturales u otras Convenciones pertinentes al asunto en disputa, aplicando los principios del Derecho de Integración y del Derecho Internacional.

Es de esta manera que la Corte Centroamericana de Justicia podría poner en vigencia los Derechos Económicos, Sociales y Culturales, mediante sus propias competencias, particularmente, aplicando el artículo 22 literal c), e) y g) de su Convenio de Estatuto. 